treatment it could mean that the patient was receiving months of unnecessary, ineffective, and expensive treatment.

Ultrasound is likely to prove useful in detecting spontaneous gall-stone recurrence and in monitoring the efficacy of postdissolution treatments given in attempts to prevent recurrence. If recurrent stones are detected, however, and treatment options include the possibility of further dissolution therapy, supplementary oral cholecystography will again be necessary.

In our present state of ignorance, we agree that it seems sensible to use both cholecystography and ultrasonography of the gall bladder in monitoring the response to medical treatment and in the follow-up of patients after "confirmed" complete gall-stone dissolution. Indeed, this has been our policy since reliable ultrasonography first became available at Guy's Hospital. The routine use of both techniques is also part of the protocol of the British National Gall-stone Group in their multicentre, postdissolution trial. But to return to $\mathrm{Dr}$ Somerville and colleagues' title question: are we being misled? We do not think so, but we do not know and until the incidence of false-positive and false-negative results with both imaging techniques becomes established, we believe that we should keep an open mind and avoid dogma.

\section{R HERMON DOWLING} David C RUPPIN

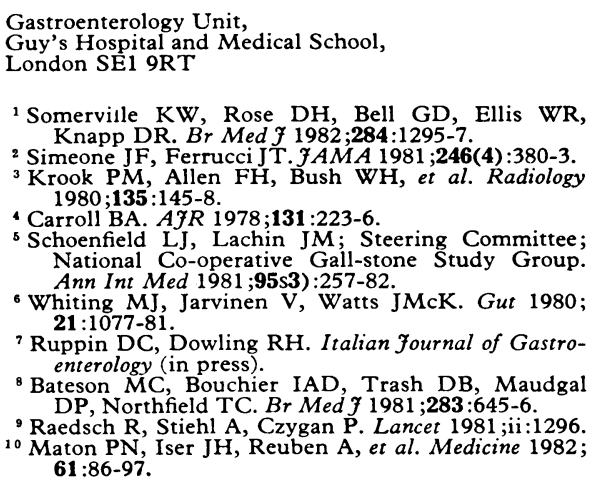

${ }^{1}$ Somerville KW, Rose DH, Bell GD, Ellis WR, Knapp DR. Br Med f 1982;284:1295-7.

imeone JF, Ferrucci JT. FAMA 1981 ;246(4) :380-3. Krook PM, Allen 1980;135:145-8. $978 ; 131: 223-6$.

5 Schoenfield LJ, Lachin JM; Steering Committee; National Co-operative Gall-stone Study Group. Ann Int Med 1981;95s3):257-82

6 Whiting MJ, Jarvinen V, Watts JMcK. Gut 1980; $21: 1077-8$

Ruppin DC, Dowling RH. Italian fournal of Gastroenterology (in press).

Bateson MC, Bouchier IAD, Trash DB, Maudgal DP, Northfield TC. Br Med f 1981;283:645-6.

${ }_{10}^{9}$ Raedsch R, Stiehl A, Czygan P. Lancet $1981 ;$;i :1296. $61: 86-97$.

\section{Nine months' chemotherapy for pulmonary tuberculosis}

SIR,-In his letter (8 May, p 1409) Professor H A Buechner condemns the British Thoracic Association (BTA) studies ${ }^{1-3}$ because he disagrees with the validity of the definitions of treatment success and relapse. These criticisms were answered and refuted in detail last year ${ }^{4}$ but despite this he persists undeterred in publishing his views again, without evidence to support them. We therefore point out once more some of the main flaws in his arguments.

His definition of treatment success is that "the patient's sputum should be rendered negative by both smear and culture at least six months prior to the completion of therapy and remain negative for life." Any positive smear or positive culture he regards as evidence of "true relapse." His definitions, which are purely arbitrary, are unsupported by any scientific evidence. Prolonged and careful follow-up of patients after short-course chemotherapy in both BTA studies and other large studies reveal that sputum specimens which are positive on smear but negative on culture may occur during or after the end of treatment in patients who progress satisfactorily both clinically and radiographically and whose sputum cultures remain persistently negative. An isolated positive culture is one which is preceded and followed by serial successive negative cultures. These isolated positive cultures are likewise not found to be related to clinical, radiological, or bacteriological relapse when patients are subject to detailed prolonged follow-up..$^{5-8}$

It is nine years since the intake of the first BTA study was completed and we remain confident about the safety and efficacy of nine months' chemotherapy with rifampicin and isoniazid plus ethambutol in the first two months, a programme which is currently recommended by both British and American thoracic societies. A closely similar nine-month regimen has proved very effective in French studies. ${ }^{9}$ The success of six-month regimens in Britain has been reported recently by the BTA. ${ }^{10}$ Dr Buechner's insistence that patients must be followed for life before a conclusion is drawn is absurd, as pointed out in a recent annotation in the Lancet, ${ }^{11}$ since under these circumstances we should still be waiting for the results of the first streptomycin trials.

Not content with restating his own views and ignoring evidence to the contrary, Dr Buechner alleges that Welsh physicians who were observed by Monie and others ${ }^{12}$ to be using chemotherapy regimens other than the BTA recommended regimen did so because they doubted the validity of the BTA studies. This is an unjustified assumption. There is always a delay between the publication of a successful chemotherapy regimen and its use in routine practice. Preliminary analysis of a more recent study in England and Wales shows that the duration of chemotherapy was 12 months or less for well over half the patients with pulmonary tuberculosis who completed their treatment (personal communication from Medical Research Council Tuberculosis and Chest Diseases Unit).

Dr Buechner has failed to respond to requests to provide evidence for his arbitrary definitions of success. We prefer to base our evaluation of success upon the prolonged observation of large numbers of patients by ourselves and others. ${ }^{313}$ On this basis we remain confident in recommending the BTA nine-month regimen as a reliable treatment for pulmonary tuberculosis.

\section{K M Citron}

$\mathrm{J}$ H ANGEL

A R SOMNER

J SELKON

Research Committee of the

British Thoracic Association,

Brompton Hospital,

1 British Thoracic and Tuberculosis Association. Lancet $1975 ;$; :119-24.

Thoracic and Tuberculosis Association. Lancet 1976 ;ii: $1102-4$

Lancet 1980;i:1182-3. Citron KM, Angel JH, Somner AR. Am Rev Respir

Dis $1981 ; 124: 658$.
5 Velu S, Andrews RH, Angel JH. Bull WHO 1961 25:409.

Dawson JJY, Devadatta S, Fox W, et al. Bull WHO $1966 ; 34: 533$.

East African/Medical Research Council. Lancet 1973; ; :1331-8.

Mitchinson DA, Keys AB, Edwards EA, et al. Tubercle 1980;61:135.
Brouet G, Roussel G. Rev Fr Maladies Respir 1977; suppl 1:5. British Thoracic Association. Am Rev Respir Dis
1982 (in press).

Anonymous. Lancet 1982; : 1163-4. Monie RDA, Hunter AM, Rocchicioli K, et al
BrMed $\mathcal{F} 1982 ; 284: 571-3$.

East African and British Medical Research Councils. Am Rev Respir Dis 1977;116:3.

\section{Increase in antibiotic resistance in}

\section{Haemophilus influenzae in the}

United Kingdom since 1977

SIR,-In the report of the study group (29 May, $p$ 1597) an increase in the prevalence of antibiotic-resistant strains of Haemophilus influenzae is noted and, of the 115 strain resistant to ampicillin, 106 produced $\beta$ lactamase. This indicates that at the time this survey was carried out non- $\beta$-lactamase- producing but nevertheless ampicillin-resistant haemophili were uncommon. The contribution of this laboratory to the survey was a total of 37 strains, showing no $\beta$-lactamase-negative but ampicillin-resistant strains. However, this year we have isolated at least six strains with an ampicillin minimum inhibitory concentration of $\geqslant 4 \mathrm{mg} / \mathrm{l}$ which were $\beta$-lactamase negative (as determined by the nitrocefin test $^{1}$ ). It would be interesting to know if others have seen this sudden apparent increase in strains of this sort, as obviously the importance of this observation lies in the fact that such strains would be resistant to the combination of ampicillin and a $\beta$-lactamase inhibitor, such as augmentin. Indeed, disc testing with augmentin and ampicillin in parallel has shown that the zone size round $30-\mu \mathrm{g}$ augmentin and $10-\mu \mathrm{g}$ ampicillin discs is, as one would expect, exactly the same with these strains; whereas with $\beta$-lactamase-producing strains the inhibition zone round the augmentin disc is much greater than that with ampicillin alone.

Because of the high content of ampicillin in augmentin sensitivity discs, a zone of inhibition is produced which could mislead those who are not aware of the existence of $\beta$-lactamase-negative ampicillin-resistant $H$ influenzae in their material into believing that augmentin should be used in such cases. It is important therefore that all laboratories should test ampicillin-resistant strains for the production of $\beta$-lactamase before recommending augmentin as an alternative antibiotic in the management of cases.

\section{Department of Laboratory \\ Medicine,}

Ruchill Hospital,

${ }^{1}$ O'Callaghan CH, Morris A, Kirby SM. Antimicrob Agents Chemother 1972;1:283-8.

\section{Severe bleeding disorders in children with normal coagulation screening tests}

SIR,-Surely the "lesson of the week" to be learnt from Dr G P. Taylor's self-critical article (19 June, p 1851) is that the proper way for a paediatrician to initiate the laboratory investigation of a child with suspected nonaccidental injury is to seek the advice of a haematological colleague, and to. leave the choice of appropriate laboratory tests to him in the light of his clinical appraisal. The clinical histories of his cases 1 and 2 are typical of coagulation and platelet disorders respectively and would surely have led any reasonably experienced haematologist to select the appropriate battery of tests for each case. $\mathrm{He}$ would not need to be told that a poor venepuncture may invalidate the results of clotting tests, and would certainly not have accepted the initial findings in case 1 as excluding a coagulation disorder. Dr Taylor's lessons, in other words, are learnt by haematologists in their professional cradles.

R M HARDISTY

Hospital for Sick Children, London WC1N 3JH

SIR,-Dr G P Taylor (19 June, p 1851) sets out a series of tests with which to screen for possible bleeding disorders in children in the hope that pathological bleeders will not be missed. Even with his list, however, he would still have missed case 1 , the severe haemo- 